Grenek: Jurnal Seni Musik Vol. 10 No. 1 (Februari 2021) page 15-28

Prodi Pendidikan Musik FBS Unimed

p-ISSN 2301- 5349

e-ISSN 2579-8200

\title{
ANALISIS BENTUK, MAKNA DAN FUNGSI LAGURURA SILINDUNG ARANSEMEN ERIZON RASIN KOTO KARYA GURU NAHUM SITUMORANG
}

\author{
Dedi Saputra Pasaribu1, Theodora Sinaga ${ }^{2}$ \\ Program Studi Pendidikan Musik, Fakultas Bahasa dan Seni Universitas Negeri \\ Medan Jalan Willem Iskandar Pasar V Medan Estate 20221, \\ Sumatera Utara-Indonesia \\ Email: ${ }^{1}$ dedipasaribu1998@gmail.com
}

\begin{abstract}
ABSTRAK
Penelitian ini bertujuan untuk mengetahui bentuk, makna, dan fungsi lagu Rura Silindung aransemen Erizon Rasin Koto. Penelitian ini bersifat deskriptif kualitatif. Hasil penelitian membuktikan bahwa bentuk lagu Rura Silindung memiliki 6 motif dengan penambahan coda pada bar 33-36, memiliki 4 frase yang terdiri dari dua frase pertanyaan dan 2 frase jawaban, lagu ini juga merupakan lagu dua bagian yang terdiri dari A (a-a') dan B (b-b'). Melodi, harmoni, dan ritme memiliki gaya dan karakteristik musik Samba, namun tetap dikolaborasikan dengan intrumen musik etnis Batak Toba, sehingga kesan dan nilai tradisi dari musik Batak Toba masih terlihat jelas. Namun terdapat kekurangan pada aransemen ini yaitu pada melodi $\mathrm{ml}$ yang mengalami ketidaksesuain dengan makna syairnya. Lagu Rura Silindung yang diaransemen oleh Erizon Rasin koto ini merupakan karya dari komponis besar yang berasal dari Tanah Batak yaitu Guru Nahum Situmorang. Lagu ini memiliki makna akan keindahan alam Lembah Silindung, mewakili hati dan kehidupan masyarakat Silindung yang hidup damai, tentram dan saling berdampingan, lagu ini melambangkan ciri khas masyarakat Silindung. Lagu ini berfungsi sebagai lagu iringan pada berbagai acara adat, dan berfungsi sebagai lagu iringan pada pesta tahunan pada acara Panen Raya di Silindung, Tarutung.
\end{abstract}

Kata Kunci : Analisis Bentuk, Makna, Fungsi, 
Grenek: Jurnal Seni Musik Vol. 10 No. 1 (Februari 2021) page 15-28

Prodi Pendidikan Musik FBS Unimed

p-ISSN 2301- 5349

e-ISSN 2579-8200

\begin{abstract}
This study aims to see the form, meaning, function, and arrangement of the song Rura Silindung, arranged by Erizon Rasin Koto. The theory used in this study includes the notion of meaning, music, musical form, meaning, function and arrangement. This study uses a descriptive qualitative research method, namely a research method that aims to describe in detail and clearly a phenomenon that is the focus of research. From this research, it shows that the song Rura Silindung arrangement Erizon Rasin Koto has 6 motives along with the supporting results with coda on bar 33 -36, has 4 phrases consisting of two question phrases and 2 answer phrases, this song is also a two part song consisting of $A\left(a-a{ }^{\prime}\right)$ and $B\left(b-b^{\prime}\right)$. We can see and hear the arrangement in this song from the melody, harmony, and rhythm arrangements which indicate that this song arrangement has the style and material of Samba music, but is still collaborated with Toba Batak ethnic music instruments, so that the impression and traditional value of the Toba Batak in the song This is still visible. However, there are deficiencies in this arrangement, namely the $\mathrm{ml}$ melody which experiences a mismatch with the meaning of the lyrics. The song Rura Silindung, which was composed by Erizon Rasin Koto, is the work of a great composer who comes from Batak Land, namely Guru Nahum Situmorang. This song has the meaning of the natural beauty of the Silindung Valley. This song also represents the hearts and lives of the Silindung community who live in peace, serenity and side by side, this is what makes this song a function of the Silindung community's signature song, Tarutung, which is sung every year both the event Great Harvest and other Traditional events in Silindung, Tarutung.
\end{abstract}

\title{
Key Words : Shape Analysis, Meaning, Function Arrangement
}

\section{PENDAHULUAN}

Musik merupakan sebuah penghayatan isi hati seseorang baik dalam perasaan senang dan sedih yang diungkapkan dalam bentuk bunyi yang teratur dengan melodi, ritme serta mempunyai unsur atau keselarasan yang indah didengar. Indonesia sebagai negara kepulauan memiliki instrumen musik daerah dan budaya yang beraneka ragam yang disebut musik daerah. Lagu daerah atau musik daerah adalah musik yang berasal dari suatu daerah tertentu dan menjadi populer dinyanyikan baik oleh rakyat daerah tersebut maupun rakyat lainnya. Pada umumnya pencipta lagu daerah ini tidak diketahui lagi alias no name (Wikipedia). Musik daerah adalah musik yang lahir dari budaya daerah dan diwariskan secara turun temurun yang secara umum disebut musik tradisional. Oleh karena itu alat musik maupun lagunya menjadi sifat unsur kesederhanaan dan kedaerahan.

Sumatera Utara adalah salah satu Provinsi di Indonesia yang terdapat beragam instrumen musik dan lagu-lagu daerah. Suku Batak Toba merupakan salah satu suku yang terdapat di daerah Sumatera Utara, suku Batak Toba juga memiliki ragam instrumen musik tradisional baik ritmik juga melodi. Suku Batak Toba memiliki lagu-lagu daerah yang telah lama lahir bahkan sebelum Indonesia Merdeka. Salah satu komponis legendaris yang tidak asing lagi bagi masyarakat Batak Toba adalah Nahum Situmorang (Alm) lahir di Sipirok, Sumatera Utara pada tanggal 14 Februari 1908 dan meninggal di Medan, Sumatera Utara pada tanggal 20 Oktober 1969 tutup usia 61 Tahun. Salah satu lagu karya Nahum Situmorang yang terkenal dan tidak asing dikalangan suku Batak Toba adalah lagu Rura Silindung, lagu ini diciptakan oleh Nahum Situmorang pada saat ia 
menghabiskan masa mudanya di Tarutung (Silindung). Nahum membuat lirik demi lirik yang membuat masyarakat Silindung bangga akan lagu tersebut, hingga akhirnya lagu tersebut sudah seperti "Lagu Kebangsaan" bagi masyarakat Silindung. Seiring dengan berjalannya waktu, banyak orang Batak yang sudah mulai lupa dengan lagu tersebut, bahkan pada saat sekarang lagu tersebut mulai tenggelam dan sangat jarang diperdengarkan lagi ditengah-tengah masyarakat khususnya di Sumatera Utara, disebabkan oleh bermunculan lagu-lagu yang lebih modern dan juga kemajuan teknologi.

Untuk itu diperlukan kreatifitas supaya lagu Rura Silindung tidak punah ditelan zaman, salah satunya dengan mengaransemen lagu tersebut supaya lebih easy listening khususnya bagi generasi muda. Aransemen merupakan kegiatan menggubah sebuah karya musik dengan tujuan memperindah karya tersebut tanpa mengkhianati melodi asli dan makna yang terdapat pada karya musik tersebut. Erizon Rasin Koto, seorang pendidik seni musik beliau beretnis Padang dan menamatkan Pendidikan S2 di Pasca Sarjana Universitas Sumatera Utara, beliau juga seorang penggiat Seni. Banyak aransemen beliau yang sudah ditampilkan, salah satu alasan mengapa Erizon Rasin Koto mengangkat kembali lagu-lagu tradisonal yang diaransemen agar tidak menghilangkan esensi nilai dan tradisi budaya dalam lagu tersebut, khususnya pada lagu Rura Silindung.

Dari kesepuluh lagu tradisional yang diaransamen oleh Erizon Rasin Koto dalam acara Pertunjukkan Drudella Orchestra Univesitas Negeri Medan, salah satunya yaitu lagu tradisional Batak Toba yang berjudul Rura Silindung. Aransemen lagu Rura Silindung tersebut telah dipertunjukkan sebanyak dua kali dikalangan kampus bahkan diluar kampus oleh mahasiswa Program Pendidikan Musik Universitas Negeri Medan. Pertunjukkan pertama pada tanggal 03 Mei 2019 dalam acara The $1^{\text {st }}$ Concert Of Drudella Orchestra yang bertemakan : The Beautiful Journey Of Traditional Songs di Auditorium Universitas Negeri Medan, kedua pada tanggal 17 Desember 2019 dalam acara The $2^{\text {nd }}$ Concert Of Drudella Orchestra yang berthemakan : Indahnya Harmoni di Adventist Convention Hall Jl. R.A Kartini No.17 Medan Polonia (konser diluar kampus). Beberapa kalangan masyarakat dan juga pelaku seni sangat mengapresiasi kedua pertunjukkan musik tersebut.

Menurut narasumber yang lahir di Tarutung Lumir Br Simanungkalit, lagu Rura Silindung menceritakan tentang keindahan Lembah Silindung di Tarutung karya Guru Nahum Situmorang. Berdasarkan latar belakang diatas, penulis merasa tertarik untuk meneliti lagu Rura Silindung yang diaransemen oleh Erizon Rasin Koto yang terkait dengan bentuk, makna dan fungsinya.

\section{Tujuan}

1. Untuk mengetahui analisis bentuk lagu Rura Silindung aransemen Erizon Rasin Koto Karya Guru Nahum Situmorang.

2. Untuk mengetahui aransemen lagu Rura Silindung oleh Erizon Rasin Koto Karya Guru Nahum Situmorang.

3. Untuki mengetahui makna yang terkandung pada lagu Rura Silindung aransemen Erizon Rasin Koto Karya Guru Nahum Situmorang.

4. Untuki mengetahui fungsi lagu Rura Silindung aransemen Erizon Rasin Koto Karya Guru Nahum Situmorang. 
Grenek: Jurnal Seni Musik Vol. 10 No. 1 (Februari 2021) page 15-28

Prodi Pendidikan Musik FBS Unimed

p-ISSN 2301- 5349

e-ISSN 2579-8200

\section{Pembahasan}

\section{A. Bentuk Lagu Rura Silindung Aransemen Erizon Rasin Koto Karya Guru Nahum Situmorang}

Lagu ini disusun dalam Formasi Choir (SATB) serta di iringi dengan ansambel orkestra dan dikolaborasikan dengan instrumen tradisi Batak Toba. Keseluruhan melodi lagu pada aransemen Erizon Rasin Koto ini dibawakan oleh sopran. Lagu Rura Silindung aransemen Erizon Rasin Koto Karya Guru Nahum Situmorang menggunakan tanda kunci 1 mol $(\mathrm{F}=\mathrm{do})$ yang terdiri dari 35 bar dengan tempo $115 \mathrm{MM}$ (Metronome Measure) dan birama 4/4. Sebagai langkah awal dari analisis ini, penulis akan memulai dengan menganalisis motif beserta teknik pengembangan yang terdapat pada lagu Rura Silindung aransemen Erizon Rasin Koto Karya Guru Nahum Situmorang.

\section{Analisis Motif}

Bar 1-2 merupakan motif 1 (m1), bar 3-4 merupakan motif 2 (m2). Pada bar 5-6 merupakan motif 3 (m3) dan dilanjutkan pada bar 7-8 merupakan motif 4 (m4).

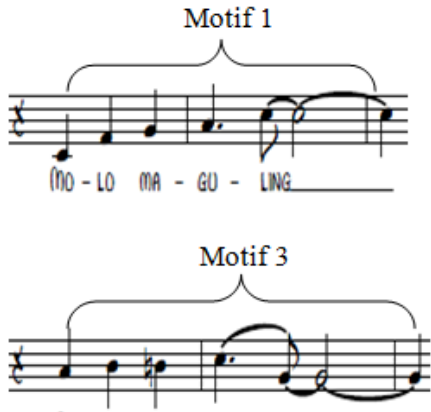

SO - LOR - MA - RO

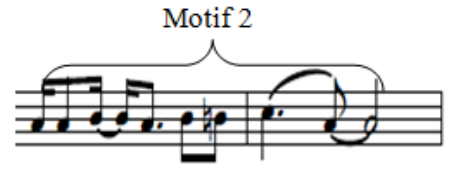

SI DU-MA-DANG A-PI -

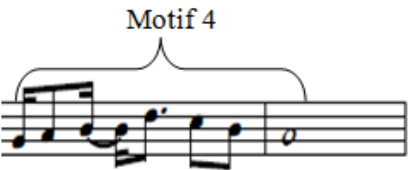

SI RO- MON-DANG BO-LAN - I

Gambar 3.1 Motif

Bar 9-10 merupakan pengulangan harafiah dari motif sebelumnya yaitu motif 1 (m1), bar 11-12 juga merupakan pengulangan harafiah dari motif sebelumnya motif 2 (m2). Pada bar 13-14 merupakan pengulangan harafiah dari motif sebelumnya yaitu motif motif 3 (m3) dan bar 15-16 merupakan motif dengan teknik sekwen turun dari motif keempat dengan variasi (m4').

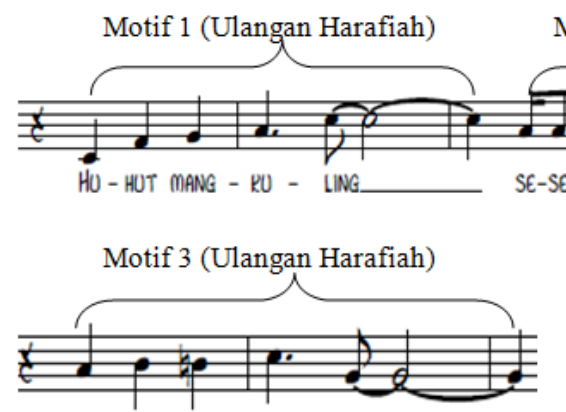

LAO MA-NGEN - DE - HON
Motif 2 (Ulangan Harafiah)

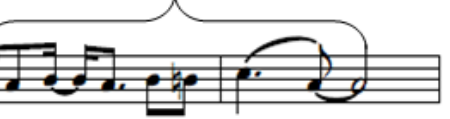

Motif 4' (Sekwen Turun)

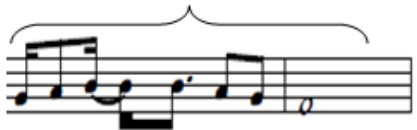

RU-PA SI-LIN-DUNG NA-U - LI

Gambar 3.2 Motif 
Grenek: Jurnal Seni Musik Vol. 10 No. 1 (Februari 2021) page 15-28

Prodi Pendidikan Musik FBS Unimed

p-ISSN 2301- 5349

e-ISSN 2579-8200

Bar 17-18 merupakan motif baru yaitu motif 5 (m5) dan bar 19-20 motif 6 (m6). Bar 21-22 pengulangan harafiah dari motif sebelumnya yaitu motif 3 (m3) serta bar 23-24 juga merupakan pengulangan harafiah dari motif sebelumnya yaitu motif $4(\mathrm{~m} 4)$.
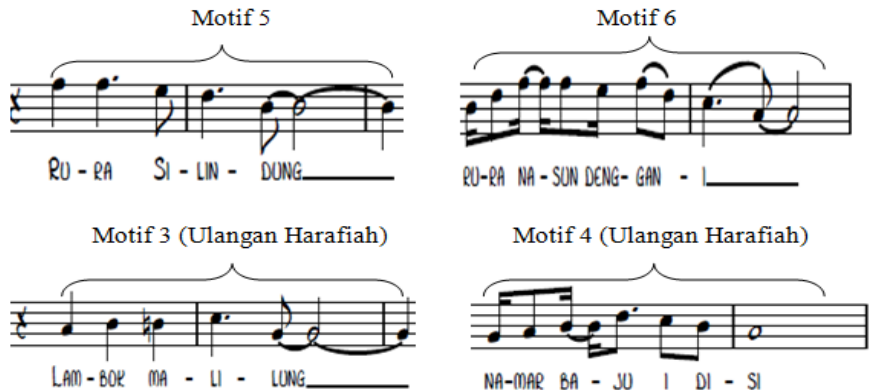

Gambar 3.3 Motif

Bar 25-26 merupakan pengulangan harafiah dari motif sebelumnya yaitu motif 5 (m5) dan bar 27-28 juga merupakan pengulangan harafiah dari motif 6 (m6). Bar 29-30 merupakan pengulangan harafiah dari motif sebelumnya yaitu motif 3 (m3) serta bar 31-32 juga merupakan pengulangan harafiah dari motif sebelumnya yaitu motif 4' (m4').

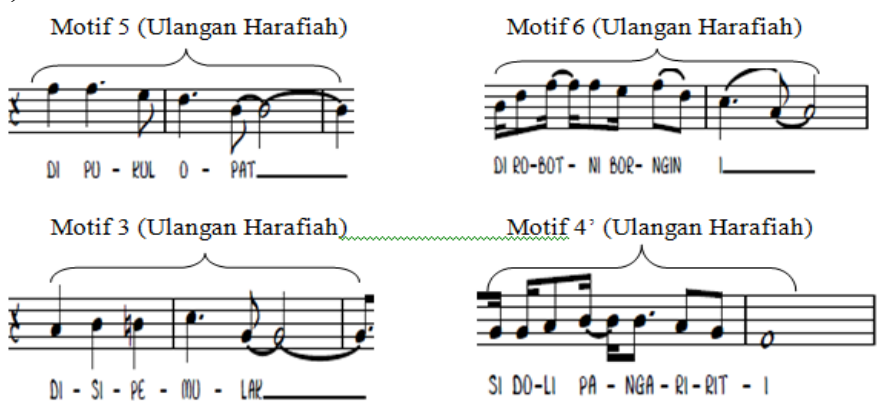

Gambar 3.4 Motif

Pada bar 33-36 arranger menambahkan coda sebagai tambahan singkat pada akhir lagu untuk menutup sebuah lagu dan mempertegas keseluruhan unsur yang terkandung pada lagu baik melodi, ritme, harmoni serta maknanya. Hanya yang mengandung melodi yaitu pada bar 33-34, dan pada bar 35-36 merupakan spoken like berupa pengucapan kata Horas yang sangat keras dari seluruh penyanyi pada Choir sebagai sapaan dan salam tradisi masyarakat Batak Toba kepada peserta yang hadir menyaksikan pertunjukkan (audience). 
Grenek: Jurnal Seni Musik Vol. 10 No. 1 (Februari 2021) page 15-28

Prodi Pendidikan Musik FBS Unimed

p-ISSN 2301- 5349

e-ISSN 2579-8200



$R O-R A S I-L I N-$ DUNG NA - U - LI HO- RAS.

Gambar 3.5 Coda

\section{Analisis Frase dan Bentuk}

1. Frase Pertama Bentuk A (a)

Pada bar ke 1-8 merupakan frase anteseden/pertanyaan (a) yang terdiri dari motif 1 , motif 2 , motif 3 , dan motif 4 .

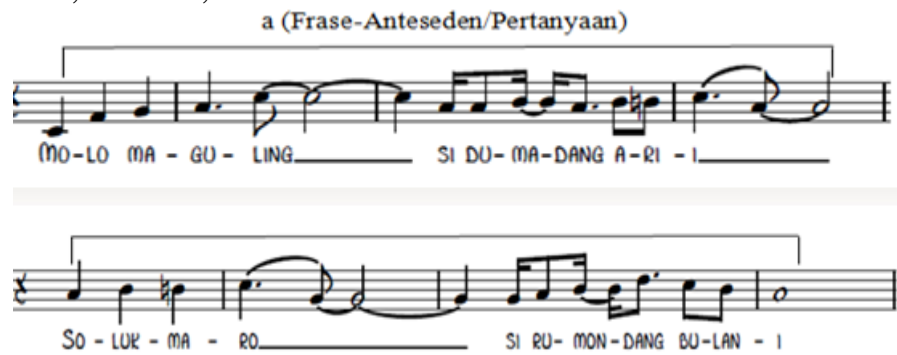

Gambar 3.6 Frase Pertama (anteseden/pertanyaan)

2. Frase Kedua Bentuk A (a')

Pada bar ke 9-16 merupakan frase konsekuen/jawaban (a'), frase pertanyaan (a) diulang secara bervariasi sebagai jawaban dengan menggunakan teknik pengembangan motif ulangan harafiah dari morif sebelumnya yaitu motif 1 dan motif 2, motif 3 ulangan harafiah dan bervariasi pada motif 4' sekwen turun. a' (Frase-Konsekuen/Jawaban)

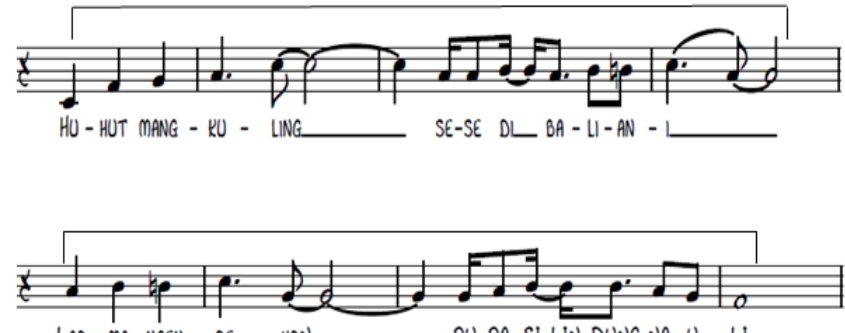

LAO MA-NGEN - DE - HON_ RU-RA SI-LIN-DUNG NA-U - LI

Gambar 3.7 Frase Kedua (konsekuen/jawaban)

3. Frase Ketiga Bentuk B (b)

Bar ke 17-24 merupakan frase anteseden/pertanyaan (b) yang terdiri dari motif 5 dan motif 6 , dengan teknik pengembangan motif ulangan harafiah dari motif sebelumnya motif 3 dan motif 4 . 
Grenek: Jurnal Seni Musik Vol. 10 No. 1 (Februari 2021) page 15-28

Prodi Pendidikan Musik FBS Unimed

p-ISSN 2301- 5349

e-ISSN 2579-8200


Gambar 3.8 Frase Ketiga (anteseden/pertanyaan)

4. Frase Keempat Bentuk B (b')

Bar ke 25-32 merupakan frase konsekuen/jawaban (b'), frase pertanyaan (b) diulang secara bervariasi sebagai jawaban dengan menggunakan teknik pengembangan motif ulangan harafiah dari motif sebelumnya yaitu motif 5 dan motif 6, motif 3 dan bervariasi pada motif 4' sekwen turun.

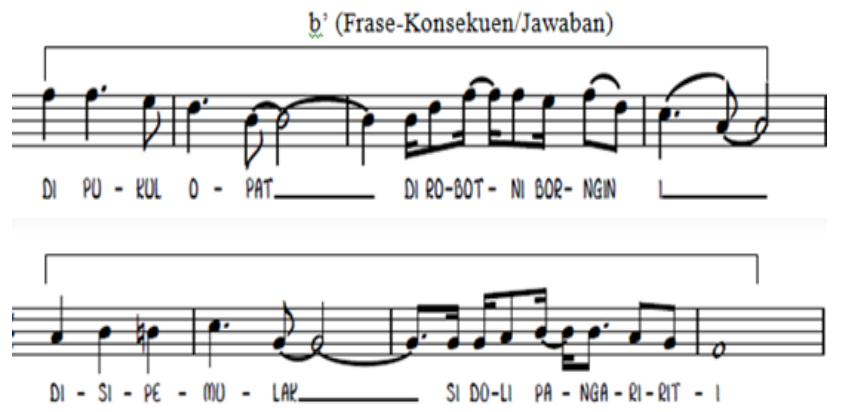

Gambar 3.9 Frase Keempat (konsekuen/jawaban)

\section{B. Lagu Rura Silindung Aransemen Erizon Rasin Koto Karya Guru Nahum Situmorang}

Lagu Rura Silindung aransemen Erizon Rasin Koto Karya Guru Nahum Situmorang merupakan salah satu dari kesepuluh lagu tradisional Sumatera Utara yang dibawakan pada saat acara The $1^{\text {st }}$ Concert Of Drudella Orchestra yang bertemakan: The Beautiful Journey Of Traditional Songs di Auditorium Universitas Negeri Meda, dan pada acara The $2^{\text {nd }}$ Concert Of Drudella Orchestra yang bertemakan: Indahnya Harmoni di Adventist Convention Hall Jl. R.A Kartini No.17 Medan Polonia (konser diluar kampus). Lagu ini tentunya memiliki perbedaaan dari lagu aslinya yang banyak dipopulerkan oleh artis-artis Batak seperti yang dibawakan oleh Victor Hutabarat dalam Album Evergreen Pop Batak Vol 2 dengan menggunakan nada dasar yang berbeda yaitu $\mathrm{G}=$ do dan dengan tempo $70 \mathrm{MM}$.

Berikut proses jalannya lagu Rura Silindung aransemen Erizon Rasin Koto Karya Guru Nahum Situmorang dimulai dengan introduksi yang dibawakan oleh instrumen dari Ansambel Drudella Orchestra yaitu sebanyak 8 bar dengan tempo Allegro 115 MM dengan kolaborasi instrumen tradisional Batak Toba yaitu Sulim, Tagading serta Ogung (improvisasi musik tradisi Batak Toba) dengan akor tingkat I pada nada dasar $\mathrm{F}=\mathrm{do}$ dan pada bar ke 8 merupakan akord tingkat $\mathrm{V}$ (Fill In) untuk menandakan bahwa bagian lagu dimulai. 
Grenek: Jurnal Seni Musik Vol. 10 No. 1 (Februari 2021) page 15-28

Prodi Pendidikan Musik FBS Unimed

p-ISSN 2301- 5349

e-ISSN 2579-8200

Kemudian dilanjut dengan bagian partitur lagu yang dinyanyikan secara bersamaan dalam bentuk Choir (SATB) dengan nada dasar yang sama F=do dan melodi lagu dibawakan oleh suara Sopran dimulai dari bar 1-16 bentuk A dengan teknik pengembangan motif ulangan harafiah dan variasi sekwen turun tanpa mengubah liriknya. Pada bar 17-32 bentuk B dengan nada dasar yang sama yaitu $\mathrm{F}=$ do juga dinyanyikan secara bersamaan dalam bentuk Choir (SATB) dan melodi lagu juga dibawakan oleh sopran, dengan teknik pengembangan motif ulangan harafiah dan variasi sekwen turun. Kemudian kembali pada introduksi yang dimainkan oleh Ansambel Drudella Orchestra sebanyak 8 bar sebagai (Interlude) dan selanjutnya terjadi pengulangan dari awal lagu (bentuk A dan B) dan berkhir dengan coda (DS. All Fine to Coda) pada bar 33-36 dengan tempo yang sama Allegro 115 MM dan juga dengan nada dasar yang sama $\mathrm{F}=\mathrm{do}$.

1. Melodi (Re-Melodyzation)

Lagu Rura Silindung aransemen Erizon Rasin Koto Karya Guru Nahum Situmorang memiliki melodi dengan perbedaan yang sedikit berbeda dari aslinya yaitu lagu bar 1-2 dan di bar 9-10 dengan motif yang sama yaitu motif 1 (m1) dengan nada sol-do-re-mi-sol pada aransemen. Sedangkan pada lagu Rura Silindung versi aslinya seperti yang dinyanyikan oleh Victor Hutabarat dalam Albumnya Evergreen Pop Batak Vol 2 dengan nada dasar yang berbeda yaitu $\mathrm{G}=$ do, memiliki melodi yang berbeda dari aransemen yaitu sol-do-re-mi-mi yang juga menjadi motif 1 (m1).

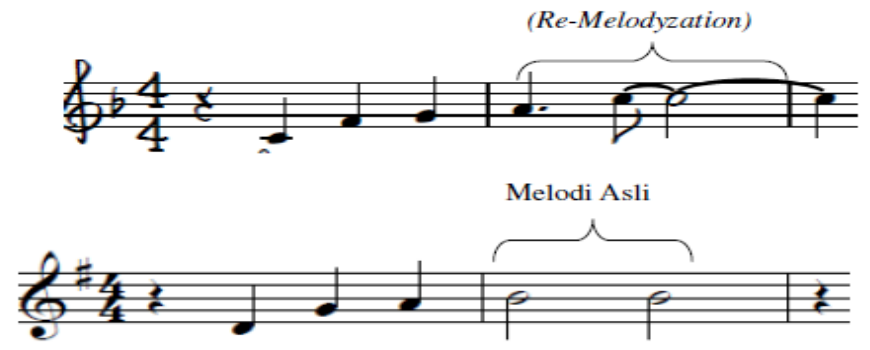

Gambar 3.10 Melodi m1 (Re-Melodyzation)

2. Harmoni (Re-Harmonization)

Pada lagu Rura Silindung aransemen Erizon Koto Karya Guru Nahum Situmorang ini terdapat banyak keindahan harmonisasi yang dilakukan oleh arranger yang dapat dilihat dan didengar bukan hanya dari musik pengiringnya saja, namun juga dapat dilihat dan didengar dari susunan suara Sopran, Alto, Tenor dan Bass (Choir), antara lain: permainan akor atau progresi akor (chord progression) yang dilakukan arranger Erizon Rasin Koto dalam aransemen ini dalam nada dasar $\mathrm{F}=\mathrm{do}$ adalah :

Akor tingkat I/I7: FM7 (F-A-C-E)/Fdominan7 (F-A-C-Es)

Akor tingkat ii: Gm7 (G-Bes-D-F)

Akor tingkat IV: BbM7 (Bes-D-F-A)

Akor tingkat V: Cdominan7 (C-E-G-Bes)

Berbeda dengan versi aslinya yang dibawakan oleh Victor Hutabarat dalam Album Evergreen Pop Batak Vol 2 yang hanya menggunakan akord pokok tingkat I- 
Grenek: Jurnal Seni Musik Vol. 10 No. 1 (Februari 2021) page 15-28

Prodi Pendidikan Musik FBS Unimed

p-ISSN 2301- 5349

e-ISSN 2579-8200

IV-V-I nada dasar $\mathrm{G}=\mathrm{do}$.

3. Ritme (Re-Rhythmization)

Seluruh ritme dalam aransemen ini mengalami modifikasi ritme dari ritme aslinya yang terdapat didalam setiap motif. Pada bar 1-2 dan 9-10 (m1) terdapat pengecilan dan pembesaran nilai nada (anticipation), Pada bar 3-4 dan 11-12 (m2) terdapat pengecilan nilai nada (syncopation dan anticipation). Pada bar 5-6, 13-14, 21-22 dan 29-30 (m3) pengecilan dan pembesaran nilai nada (anticipation. Pada bar 7-8 dan 23-24 (m4) terdapat pengecilan nilai nada (syncopation), dan bar 15-16 dan 31-32 (m4') terdapat pengecilan nilai nada (syncopation). Pada bar 17-18 dan 25-26 (m5) terdapat pengecilan dan pembesaran nilai nada (anticipation), dan pada bar 1920 dan 27-28 (m6) terdapat pengecilan nilai nada (syncopation dan anticipation).

\section{Makna Yang terkandung Pada Lagu Rura Silindung Karya Guru Nahum Situmorang}

Untuk mengetahui makna dari Lagu Rura Silindung karya komponis besar Guru Nahum Situmorang, penulis melakukan wawancara kepada narasumber pada tanggal 08 Agustus 2020 - 09 Agustus 2020. Berikut hasil wawancara dari narasumber yang penulis rangkumkan kembali berupa lirik lagu Rura Silindung beserta makna pada tabel berikut:

Tabel 3.1 Makna Lagu Rura Silindung:

\begin{tabular}{|l|l|}
\hline \multicolumn{1}{|c|}{ Lirik lagu Rura Silindung } & \multicolumn{1}{c|}{ Arti (maknanya) } \\
\hline Molo maguling si rumandang ari $i$, & $\begin{array}{l}\text { Jika berguling dan tenggelamnnya } \\
\text { matahari, } \\
\text { Muncullah bulan purnama. }\end{array}$ \\
\hline $\begin{array}{l}\text { Huhut mangkuling sese di balian I, } \\
\text { Lao mangendehon rura silindung na } \\
\text { uli. }\end{array}$ & $\begin{array}{l}\text { Sambil bernyanyi jangkrik di ladang, } \\
\text { Ingin menyanyikan keindahan Lembah } \\
\text { Silindung. }\end{array}$ \\
\hline $\begin{array}{l}\text { Rura-silindung rura na sundenggan } i, \\
\text { Lambok malilung na marbajui di si. }\end{array}$ & $\begin{array}{l}\text { Lembah Silindung lembah yang sangat } \\
\text { indah tiada duanya, } \\
\text { Berhati baik dan cantik para gadis } \\
\text { disana }\end{array}$ \\
\hline $\begin{array}{l}\text { Dipukul opat di robot ni borngin } i, \\
\text { Di si pe mulak sidoli pangaririt } i .\end{array}$ & $\begin{array}{l}\text { Di pukul empat menjelang subuh, } \\
\text { Di waktu itu pulangnya pemuda yang } \\
\text { mencari jodoh }\end{array}$ \\
\hline
\end{tabular}

Lagu Rura Silindung merupakan karya dari komponis besar Guru Nahum Situmorang yang lahir pada tanggal 14 Februari tahun 1908 di Sipirok. Sekitar tahun 1950an, Nahum Situmorang menginjakkan kaki di Silindung. Pada saat itu sedang terjadi gejolak dan kerisauan di tengah-tengah masyarakat Silindung. Kisah cinta Nahum Situmorang dengan seorang gadis cantik boru Lumbantobing yang juga mencintai Nahum Situmorang. Namun tidak banyak yang mengetahui kisah mereka, akan tetapi pada akhirnya mereka tidak berjodoh dan Nahum Situmorang meninggal pada tanggal 20 Oktober 1969 di Medan. 
Grenek: Jurnal Seni Musik Vol. 10 No. 1 (Februari 2021) page 15-28

Prodi Pendidikan Musik FBS Unimed

p-ISSN 2301- 5349

e-ISSN 2579-8200

Makna yang terdapat dalam lagu Rura Silindung ini merupakan bentuk gagasan atau apresiasi dari isi hati dan perasaan guru Nahum Situmorang akan keindahan yang tiada tara pada Lembah Silindung (Rura Silindung). Pada lagu ini juga dia menggambarkan bagaimana kehidupan masyarakat Silindung yang hidup rukun, damai dan saling berdampingan, juga kandungan makna lainnya yaitu pada zaman dahulu lagu ini dijadikan sebagai penyemangat para pemuda yang penuh dengan perjuangan jika pergi mencari cinta sejatinya, yang harus berjalan kaki ke desa lain karena belum adanya alat transportasi pada saat itu.

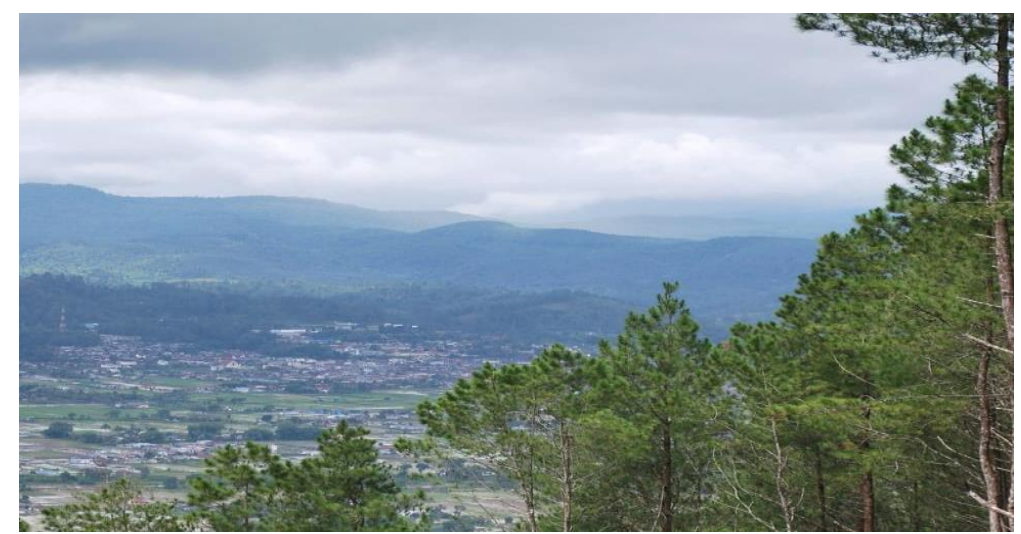

Gambar 3.11 Keindahan Alam Rura Silindung di pagi hari Tampak dari Bukit Salib Kasih Tarutung (Dokumentasi Pribadi)

Dari penjelasan diatas Penulis berkesimpulan bahwa lagu Rura Silindung sangat memperhatikan hubungan nada dengan syairnya. Pada bagian awal lagu bentuk A, guru Nahum Situmorang menciptakan nada dimulai dari nada terendah/nada bawah (sol rendah), hal ini bertujuan untuk menggambarkan bagaimana matahari yang terbit dari sebelah Timur dengan pergerakan dari bawah ke atas dan pada sore menjelang malam mulai tenggelam kembali ke bawah dengan perlahan dan mulus dari sebelah Barat. Pada bagian awal lagu bentuk B, guru Nahum Situmorang menciptakan nada dimulai dari nada tertinggi/nada atas (do tinggi), hal ini bertujuan untuk menggambarkan bagaimana kita bisa melihat dan menikmati keindahan Rura Silndung harus melalui ketinggian yaitu tepatnya berada pada bukit aatu puncak Siatas Barita, Salib Kasih Tarutung. 
Grenek: Jurnal Seni Musik Vol. 10 No. 1 (Februari 2021) page 15-28

Prodi Pendidikan Musik FBS Unimed

p-ISSN 2301- 5349

e-ISSN 2579-8200

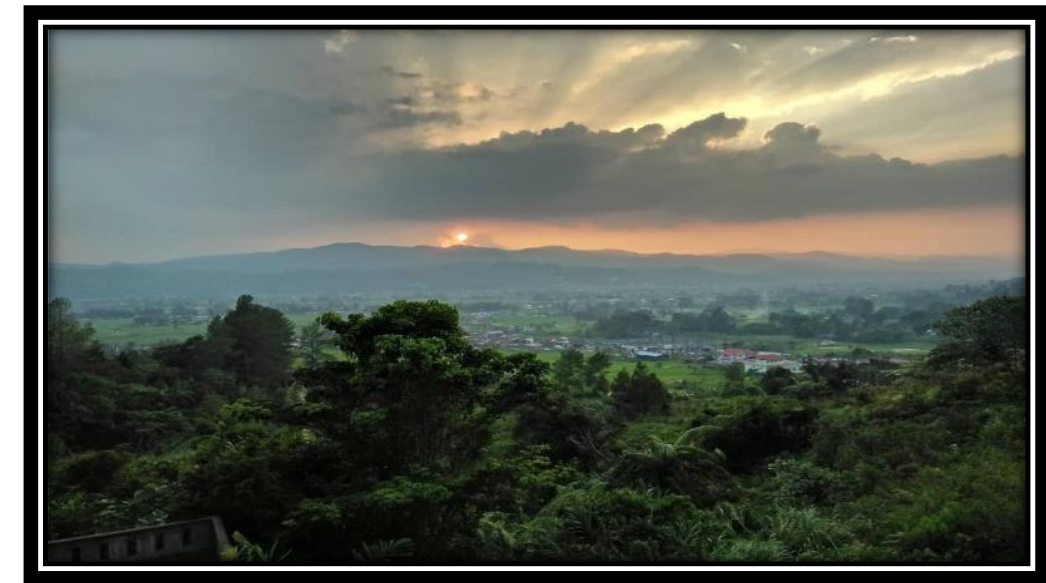

Gambar 3. 12 Keindahan Alam Rura Silindung menjelang malam hari Tampak dari Bukit Salib Kasih Tarutung (Dokumentasi Pribadi)

\section{Fungsi Lagu Rura Silindung Karya Guru Nahum Situmorang}

Lagu Rura Silindung karya Guru Nahum Situmorang pada tahun tahun 1950-an dan sampai sekarang (2020) berfungsi sebagai lagu iringan yang selalu dinyanyikan dalam acara Panen Raya di Silindung (Tarutung), berfungsi sebagai lagu iringan pada acara adat, dan berfungsi sebagai lagu iringan pada pesta tahunan. Dengan demikian lagu ini semakin dekat dihati masyarakat Silindung dan menjadi lagu khas masyarakat Silindung. Lagu Rura Silindung ini juga menggambarkan bagaimana kehidupan masyarakat setempat yang hidup rukun, damai dan tentram, sehingga lirik dan melodi dari lagu ini sudah mewakili perasaan masyarakat Silindung dalam kehidupan sehari-harinya. Lagu Rura Silindung ini sampai sekarang masih dipertahankan oleh masyarakat Silindung, baik dari melodi, lirik, dan makna. Pada akhirnya wujud nyata dari lagu ini mengingatkan seluruh para perantau dimana pun berada yang berasal dari daerah Silindung (Tarutung), agar selalu mengingat akan keindahan Lembah Silindung (Rura Silindung) yang merupakan tanah kelahiran yang selalu melekat di hati dan jiwa. 
Grenek: Jurnal Seni Musik Vol. 10 No. 1 (Februari 2021) page 15-28

Prodi Pendidikan Musik FBS Unimed

p-ISSN 2301- 5349

e-ISSN 2579-8200



Foto Guru Nahum Situmorang (1908-1969)

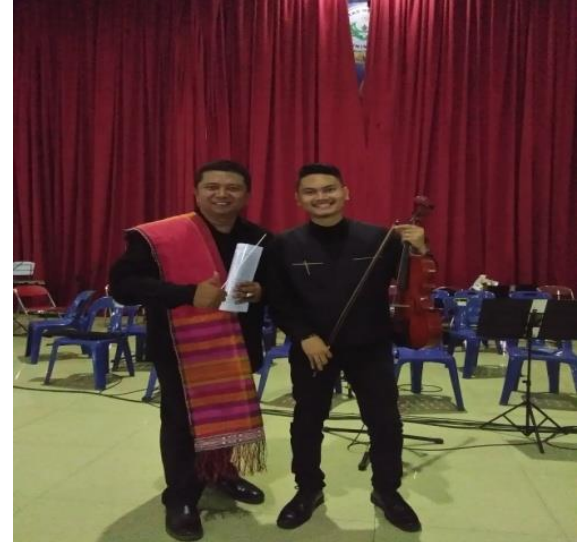

Foto Peneliti bersama Erizon Koto

(2019)

\section{Kesimpulan dan Saran}

\section{Kesimpulan}

1) Lagu Rura Silindung aransemen Erizon Rasin Koto Karya Guru Nahum Situmorang ini memiliki 6 motif beserta pendukungnya dengan penambahan coda pada bar 33-36, memiliki 4 frase yang terdiri dari dua frase pertanyaan dan 2 frase jawaban, lagu ini juga merupakan lagu dua bagian yang terdiri dari A (a-a') dan B (b-b'). Dengan penambahan coda pada bar 33-34 yang diciptakan oleh arranger berupa melodi dan pada bar selanjutnya yaitu bar 35-36 sebagai sapaan terakhir yaitu kata Horas ciri khas sapaan masyarakat Batak Toba pada umumnya yang diucapakan dengan tegas dan lantang (spoken like) oleh Choir dan Player Ansambel Orchestra.

2) Aransemen pada lagu ini dapat kita dengar dari melodi, harmoni (Chord Progression), dan ritme (Syncopation dan Anticipation) yang menandakan bahwa aransemen lagu ini memiliki gaya dan karakteristik musik Samba, namun tetap dikolaborasikan dengan intrumen musik etnis Batak Toba, sehingga kesan dan nilai tradisi dari Batak Toba pada lagu ini masih terlihat.

3) Lagu Ruras Silindung yang diaransemen oleh Erizon Rasin Koto ini merupakan karya dari komponis besar yang berasal dari Tanah Batak yaitu Guru Nahum Situmorang. Lagu ini memiliki makna akan keindahan alam pada Lembah Silindung, menggambarkan masyarakat yang hidup damai, tentram dan saling berdampingan, lagu merupakan lagu Khas masyarakat Silindung, Tarutung.

4) Lagu Rura Silindung ini diciptakan oleh Guru Nahum Situmorang pada tahun 1950an dan sampai sekarang selalu dinyanyikan dalam acara besar maupun kecil khususnya acara Panen Raya di Silindung (Tarutung), acara adat, pesta tahunan, dan lainnya. Lagu Rura Silindung menggambarkan bagaimana kehidupan masyarakat setempat yang hidup rukun, damai dan tentram, sehingga lirik lagu ini mewakili perasaan masyarakat Silindung dalam kehidupan sehari-harinya. Lagu Rura Silindung ini sampai sekarang masih dipertahankan oleh masyarakat Silindung, baik dari melodi, lirik, dan makna. 
Grenek: Jurnal Seni Musik Vol. 10 No. 1 (Februari 2021) page 15-28

Prodi Pendidikan Musik FBS Unimed

p-ISSN 2301- 5349

e-ISSN 2579-8200

\section{A. Saran}

1. Bagi masyarakat Silindung, Tarutung terutama generasi muda agar terus mempublikasikan lagu Rura Silindung ke media sosial sehingga dikenal masyarakat luas.

2. Bagi pemerintah Kota Silindung, Tarutung agar terus mensosialisasikan lagu Rura Silindung kepada masyarakat luas melalui berbagai macam kegiatan.

3. Bagi mahasiswa agar meneliti berbagai macam kebudayaan dan adat istiadat masyarakat Silindung, Tarutung, sehingga Silindung lebih dikenal luas.

\section{DAFTAR PUSTAKA}

Bonoe, Pono. 2003. Kamus Musik. Yogyakarta : Kanisinus

Budidharma, Pra. 2001. Pengantar Komposisi dan Aransemen. Jakarta: Gramedia

Damanik, Sintia I. 2015. Analisis Soundtrack Lagu Perahu Kertas Karya Dewi Lestari dalam Film Perahu Kertas. Skripsi. Untuk Mendapatkan Gelar Sarjana Pendidikan UNIMED

Djadjasudarma, 2013. Semantik 2 Pemahaman Ilmu Makna. Jakarta: Rineka Cipta

Fahmi, Ahmad A. 2017. Analisis lagu Mencari Cinta Sejati Karya Melly Goeslaw sebagai Soundtrack Film Rudy Habibie. Skripsi. Untuk Mendapatkan Gelar Sarjana Pendidikan UNIMED

Fajrina. 2015. Reprentasi Pesan Lingkungan dalam Lirik Lagu Surat Untuk Tuhan Karya Group Musik 'Kapital' (Analisis Semiotika). Jurnal. eJournal. Ilmu Komunikasi 
Grenek: Jurnal Seni Musik Vol. 10 No. 1 (Februari 2021) page 15-28

Prodi Pendidikan Musik FBS Unimed

p-ISSN 2301- 5349

e-ISSN 2579-8200

UNMUL

Firnando, kiki. 2017. Analisis Lagu Glomy Sunday (Hungarian Suicide Song) Karya Rezso Secress. Skripsi. Untuk Mendapatkan Gelar Sarjana Pendidikan UNIMED

Jamalus. 1998. Panduan Pengajaran Buku Pengajaran Musik Melalui Pengalaman Musik. Jakarta: Proyek Pengembangan Lembaga Pendidikan

Lumban Gaol, Dedi B. 2018. Analisis Teknik Bernyanyi Diana Damrau pada Opera 'The Magic Flute Aria Queen Of The Night' karya Wolfgang Amadeus Mozart. Skripsi. Untuk Mendapatkan Gelar Sarjana Pendidikan UNIMED

Machlis, Joseph. 1955. The Enjoyement of music. New York: W.W Norton \& Company, INC

Margono, S. 2014. Metodoligi Penelitian Pendidikan. Jakarta: Rineka Cipta

Moleong, lexy. 2007. Metodologi Penelitian Kualitatif. Bandung: Remaja Rosdakarya

Miller, Hugh M. 2017. Apresiasi Musik. Yogyakarta: Thafa Media Yogyakarta

Nopingsih. 2009. Istilah-Istilah Batik Tradisional Jawa. Skripsi. UNS

Prier SJ, Karl-Edmund. 1996. Ilmu Bentuk Musik. Yogyakarta: PUSAT MUSIK LITURGI

Prier SJ, Karl-Edmund, 2009. Kamus Musik. Yogyakarta: PUSAT MUSIK LITURGI

Prier SJ, Karl-Edmund, 2015. Ilmu Bentuk Musik. Yogyakarta: PUSAT MUSIK LITURGI

Sianturi, Ruth Viky. 2019. Analisis Struktur Lagu A A Sing Sing So Aransemen Bian Liunian. Skripsi. Untuk Mendapatkan Gelar Sarjana Pendidikan UNIMED

Soeharto, M. 1993. Belajar Notasi Balok. Jakarta: PT. Gramedia Widiasarana Indonesia

Stanley, S. 1998. The Grove Concise Dictionary Of Music. Oxford University Press: Revised Edition CBE

Sugiyono, 2009. Metode Penelitian Kuantitatif, Kualitatif dan R\&D. Bandung: Alfabeta Sugiyono, 2016. Metode Penelitian Kuantitatif, Kualitatif dan R\&D. Bandung: Alfabeta Sugiyono, 2017. Metode Penelitian Kuantitatif, Kualitatif dan R\&D. Bandung: Alfabeta Stanley S, 1998. The Grove Concise Dictionary Of music. Macmillan: London

Sugandi, Radyan. 2016. Aransemen dan Pola Penyajian Lagu Caping Gunung Pada Keroncong Kharisma di Desa Jagalan Banguntapan bantul Yogyakarta. Jurnal. eJournal UNY

\section{Sumber Internet :}

www.Wikipedia.com (diakses pada tanggal 04 Maret 2020)

www.kompasiana.com (diakses pada tanggal 05 Maret 2020) 